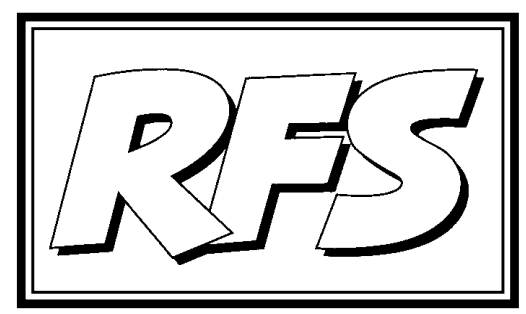

Revista de Fomento Social, 60 (2005), 333-336

\title{
Del alivio de la deuda externa a la reducción de la pobreza: el caso de Honduras
}

José J. ROMERO RODRÍGUEZ S. J.

Durante una reciente estancia en Honduras, hemos tenido ocasión de participar en una de las 17 Jornadas regionales Informativas de Actualización de la Estrategia para la reducción de la pobreza (ERP) de Honduras. Dicha reunión tuvo lugar el 6 de agosto de 2005 en Santa Rosa de Copán, capital del departamento de dicho nombre y cabecera de la región occidental de Honduras.

En este año 2005 se han sumado el proceso en marcha de la iniciativa del alivio de la deuda de los países pobres altamente endeudas del Banco Mundial y del Fondo Monetario Internacional (países conocidos por sus siglas inglesas HIPC: Highly Indepted Poor Countries), a las decisiones del G-8 en su reunión de Julio de 2005 y a las condonaciones otorgadas por el llamado Club de París (que reúne a acreedores privados). En el caso de Honduras, ello lleva consigo la reducción de más de la mitdad del total de su deuda viva 
al año 2005, que ascendía a algo más de 5.000 millones de dólares (lo que representa alrededor del $90 \%$ del PIB del país). El saldo de la deuda quedaría en unos 2.138 millones de dólares. Naturalmente, el ahorro no se produce en un solo año, pues se trata de reembolsos que el país habría de ir realizando en un periodo largo de tiempo.

Para acceder a la condonación, Honduras ha debido satisfacer los criterios de elegibilidad de los países HIPC (diciembre de 1999), alcanzar el llamado "punto de decisión" en junio de 2000 y el "punto de culminación" en marzo de 2005. El criterio decisivo consiste en que el Valor Presente Neto de la Deuda externa sea superor al 250\% de los ingresos fiscales; en el caso de Honduras dicho valor era del $320 \%$. Además necesitaba la "confianza" de los países y las instituciones multinacionales (FMI y BM) acreedoras con respecto a los siguientes requisitos básicos:

- La existencia de una ERP debidamente concertada con sus desarrollos legislativos pertinentes.

- El montaje de un sistema de seguimiento de la ERP (SIERP).

- Una reforma del sistema de Seguridad Social.

- El compromiso con el mejoramiento de los servicios básicos de salud, educación y de los indicadores sociales.

- El cumplimiento del acuedo con el FMI.

- El fortalecimiento del sector financiero.

No es éste el lugar para reseñar las críticas que se han hecho a este alivio de la deuda, unas más razonables que otras, dicho sea de paso; nuestro objetivo es informar sencillamente a los lectores interesados sobre el proceso concreto que dicha condonación pone en marcha en el país más afectado de toda América Latina en términos relativos.

La condonación de la deuda lleva consigo el compromiso formal y efectivo del país beneficiado de invertir dichos fondos en proyectos prioritarios enmarcados en la Estrategia para la Reducción de la Pobreza (ERP) previamente elaborada por el país y aprobada por los organismos internacionales acreedores. Para la aplicación de esos fondos, el gobierno de Honduras se ha tenido que dotar de una serie de instrumentos legales y procedimentales que determinan con precisión los procedimientos, mecanismos y formas institucionales que se arbitrarán para cumplir los compromisos vinculados al alivio. En efecto, el país cuenta -básicamente- con una ERP, con una Ley 
para la gestión de la reducción de la pobreza, con una Ley del Fondo para la reducción de la pobreza (FRP), con un reglamento que constituye el Consejo Consultivo de la ERP, formado por representantes del gobierno central, de las municipalidades y de la sociedad civil, con la presencia como observadores de representantes de la Comunidad Internacional. El Consejo Consultivo asesora al Gabinete social (formado por los ministros del gobierno implicados) para el establecimiento de la elegibilidad de los programas y proyectos a ser financiados con recursos del FRP.

Precisamente el proceso al que pudimos asistir consiste en la convocatoria por parte de dicho Consejo Consultivo de debates abiertos en todas las cabeceras departamentales (17 en total) para definir las prioridades de asignación del ahorro neto que se produce en los presupuestos nacionales al liberarse las cantidades previamente destinadas al pago del servicio de la deuda. Para hacerse una idea de lo que representan esos volúmenes, dichas cantidades están entre los 165 y los 170 millones de dólares anuales durante los próximos cuatro años. Se trata, sin duda, de cantidades importantes, pero tampoco tan decisivas; así, por ejemplo, los montos anuales aportados por la cooperación internacional en los últimos diez años ascienden a unos 300 millones de dólares anuales ${ }^{1}$.

Los proyectos priorizados habrán de estar focalizados en áreas de bienestar social, y distribuidos según una serie de criterios que tienen que ver con: la orientación hacia las metas de dicha Estrategia en el ámbito de la consecución de los Objetivos del Milenio; el nivel de pobreza del municipio considerado (precisamente en el occidente del país se encuentran la mayoría de los municipios hondureños con menor Índice de Desarrollo Humano según la metodología del PNUD); el número de beneficiarios de la acción. Por su parte, los criterios sectoriales dan prioridad a los indicadores siguientes: generación de empleo, satisfacción de necesidades básicas, educación, salud, agua y saneamiento y gestión de riesgos.

Un proceso de esta importancia y de este monto económico, relativamente importante, tiene el peligro de suscitar expectativas excesivas en la población y de ser manipulado con fines políticos y partidistas. Ciertamente no fue esa la impresión que sacamos al escuchar en Santa Rosa la larga intervención del ministro de Trabajo, Germán Leitzelar, comisionado del Gobierno para la

1 Véase, por ejemplo, el Informe Estratégico Nacional - Honduras, 2002-2006 de la Comisión EUROPEA. 
ejecución de la ERP. Sea de ello lo que fuera, sin embargo, albergamos dudas acerca de la capacidad del ejecutivo para proceder a la definición, evaluación y ejecución del número de proyectos necesarios con el fin de que los fondos liberados se apliquen de forma efectiva según los criterios indicados.

Por otro lado, en el encuentro al que asistimos se manifestó claramente la tensión dialéctica entre la dinámica propositiva de las organizaciones de la llamada sociedad civil(ONGs y movimientos ciudadanos de todos los ámbitos) y las propias agendas de los gobiernos central y, sobre todo, municipales; cada una de esas instancias cuenta normalmente con sus propios planes estratégicos y sus carteras de proyectos priorizados, y cada una de ellas reivindica su legitimidad como representante de los ciudadanos afectados, en particular los más pobres. Será preciso un esfuerzo notable de concertación para que esta posible discrepancia, en principio no necesariamente negativa, no paralice el proceso y que cada quien base sus propuestas en su real y efectiva legitimidad y representatividad.

$\mathrm{Si}$, además, todo el proceso comienza precisamente en un año electoral (en noviembre se celebran elecciones generales, que se presentan muy reñidas), no es tarea fácil la que espera al gobierno y a la sociedad de Honduras. En todo caso, seguiremos con atención el proceso y les deseamos todo el éxito posible en la ejecución del plan.

Los lectores interesados encontrarán más información al respecto en la página Web del sistema de información de la ERP de Honduras: www.sierp.hn 